neonates without probiotics treatment were run, $0.7 \%$ were found positive for $L$. rhamnosus, $0.4 \%$ were positive for $B$. lactis, non of the samples were positive for both. A total of 247 faecal samples from premature neonates treated with probiotics were run, $57.0 \%$ of the collected faecal samples contained both L. rhamnosus and B. lactis, $38.0 \%$ were positive only for $L$. rhamnosus, $4.4 \%$ were positive for only B. lactis and $0.6 \%$ was negative for both probiotics.

Conclusion The probiotic supplementations do reach the gastrointestinal tract and be detected. In general the rate of NEC and death were reduced in premature neonates treated with $L$. rhamnosus and B. lactis.

\section{KNOWLEDGE AND ATTITUDE OF BREAST FEEDING AMONG FEMALES IN SAUDI ARABIA}

doi:10.1136/archdischild-2012-302724.1384

${ }^{1}$ AT Alosaimi, ${ }^{1} \mathrm{M}$ Buhaisi, ${ }^{1} \mathrm{M}$ Shoukri, ${ }^{2} \mathrm{~S}$ Al-Alaiyan, ${ }^{1} \mathrm{~T}$ Alkharfi, ${ }^{1} \mathrm{~K}$ Alfelah. ${ }^{1}$ Pediatrics, King Saud University; ${ }^{2}$ Pediatrics, King Faisal Specialist Hospital \& Research Centre Riyadh, Saudi Arabia

Background As stated by the WHO, exclusive breastfeeding is unequalled for healthy growth and development in young infants. In this study; we attempted to address the attitude of females in Saudi population toward awareness and knowledge of breastfeeding.

Method An observational cross-sectional survey distributed participants who were interviewed at shopping malls in the city of Riyadh. The survey addressed socio-demographic data and attitude of eligible females toward breastfeeding exploring the benefits and reasons limiting breastfeeding practice among the population.

Results A total of 332 females were enrolled in this study. Most of the interviewed participants were Saudi, married, and had more than one child. $86 \%$ of interviewed participants believed the best way to start feeding the newborn are solely breastfeeding. $41 \%$ attended breast feeding health education. Availability of formula, cosmetic, short maternity leave from job and lack of awareness were factors believed to limit breast feeding. Mother's education, parity, and age significantly correlated with the belief that exclusive breast feeding is the best start for the newborn.

Conclusion Females in Saudi Arabia are well aware that breast feeding is the best start for the newborn. Practical steps such as intensive education, support at postnatal period and longer maternity leave are required to improve rates of exclusive breast feeding in the country.

\section{OPTIMIZING NUTRITION AFTER BIRTH WITH A UNIQUE STANDARDIZED PARENTERAL SOLUTION MAY REDUCE ELECTROLYTES ANOMALIES IN < 1250G INFANTS}

doi:10.1136/archdischild-2012-302724.1385

T Senterre, J Rigo. University of Liège, Liège, Belgium

Nutritional recommendations in VLBW infants advised to increase protein and energy intakes but also advised to avoid parenteral nutrition electrolytes intakes during the first 2-3 days of life to reduce electrolytes anomalies that are frequently observed.

The Aim of this study is to evaluate the electrolytes tolerance of an optimized nutritional program using a unique standardized parenteral nutrition solution (StPNsol) containing electrolytes from the first day of life in $<1250 \mathrm{~g}$ infants $(\mathrm{N}=102)$ during the first 15 days of life.

On the first day of life, PN intakes from the StPNsol included $38 \pm 6 \mathrm{kcal} / \mathrm{kg}^{*} \mathrm{~d}, 2.4 \pm 0.3 \mathrm{~g} / \mathrm{kg}^{*} \mathrm{~d}$ of protein, $0.8 \pm 0.4 \mathrm{mmol} / \mathrm{kg}^{*} \mathrm{~d}$ of sodium and $0.8 \pm 0.4 \mathrm{mmol} / \mathrm{kg}^{*} \mathrm{~d}$ potassium. Afterwards, nutritional intakes rapidly increased.

Hypernatremia $>150 \mathrm{mmol} / \mathrm{L}$ occurs in 16 infants (15.6\%), on 27 days (1.8\%), essentially between 1 and 3 days of life (19 days).
Hyponatremia $<130 \mathrm{mmol} / \mathrm{L}$ occurs in 31 infants $(30.4 \%)$ on 55 days (3.6\%), essentially between 1 and 7 days of life (40 days).

No infant develops a hyperkaliemia $>7 \mathrm{mmol} / \mathrm{L}$. Hypokaliemia < $3 \mathrm{mmol} / \mathrm{L}$ occurs in 9 infants (8.8\%) on 16 days (1.0\%), mainly between 1 and 3 days of life (7 days).

This study demonstrates that increasing protein and energy intakes with a StPNsol containing electrolytes from the first day of life is not associated with an increased incidence of hypernatremia or non-oliguric hyperkaliemia. Furthermore, this study seem to suggest that optimizing nutritional intakes and increasing anabolism may require higher electrolytes intakes than usually recommended during the first days of life in VLBW infants.

\section{DOES TOTAL PARENTERAL NUTRITION RAISE SERUM VITAMIN D LEVEL IN PRETERM INFANTS?}

doi:10.1136/archdischild-2012-302724.1386

${ }^{1,2,3} \mathrm{C}$ Onwumeme, ${ }^{1} \mathrm{~F}$ Martin, ${ }^{1} \mathrm{R}$ McCarthy, ${ }^{4} \mathrm{M}$ Kilbane, ${ }^{4} \mathrm{MJ}$ McKenna, ${ }^{2} \mathrm{~N}$ Murphy, ${ }^{1,3,5}$ EJ Molloy. ${ }^{1}$ Neonatal Intensive Care, National Maternity Hospital, Holles Street: ${ }^{2}$ Childrens University Hospital Temple Street; ${ }^{3}$ UCD School of Medicine \& Medical Sciences, University College Dublin; ${ }^{4}$ Metabolism Laboratory, St Vincent's University Hospital; ${ }^{5}$ Royal College of Surgeons in Ireland, Dublin, Ireland

Background Vitamin D (25OHD) plays an important role in skeletal and non skeletal health. 25OHD deficiency is common in preterm infants. Very low birth weight (VLBW) preterm infants depend entirely on total parenteral nutrition (TPN) and breast milk for their nutritional requirements during early post-natal life.

Aim To assess serum 250HD status in VLBWs and the effect of TPN on serum $250 H D$ level during early parenteral nutrition.

Methods Serum 25OHD levels were evaluated by radioimmunoassay from VLBWs at birth and immediately before commencement of oral additional vitamin $\mathrm{D}$ supplementation.

Results 22 VLBWs were included in this study and had 44 samples taken. Their mean gestational age (SD) was $28 \pm 2$ weeks and birth weight $1.2 \pm 0.4 \mathrm{~kg}$. There were 11 males and 11 females, 3 Black Africans, 1 Asian, and 18 Caucasians. The number of TPN days was $12 \pm 5$ and the daily intake of $25 \mathrm{OHD}_{3}$ from TPN was $118 \pm 45 \mathrm{IU} /$ day. The $25 \mathrm{OHD}$ content in expressed breast milk was negligible. The $250 \mathrm{HD}$ levels increased from $26 \pm 18 \mathrm{nmol} / \mathrm{L}$ (at birth) to $36.2 \pm 20 \mathrm{nmol} / \mathrm{L}$ (pre-vitamin $\mathrm{D}$ enteral supplementation) $(\mathrm{p}=0.09)$. The increase in $25 \mathrm{OHD}$ levels did not reach sufficiency $(\geq 50 \mathrm{nmol} / \mathrm{L})$. Conclusions Inadequate nutrition during the early days of preterm infants can lead to poor growth and increased morbidity. Total parenteral nutrition and breast milk are the predominant source of nutrition in early postnatal life of VLBWs. This study showed that vitamin $\mathrm{D}$ content of TPN increased $25 \mathrm{OHD}$ level but not up to sufficiency $(\geq 50 \mathrm{nmol} / \mathrm{L})$.

\section{IMPACT OF PERINATAL NUTRITION ON KIDNEY FUNCTION AT FIVE YEARS IN VERY LOW BIETH-WEIGHT CHILDREN}

doi:10.1136/archdischild-2012-302724.1387

1,2R Vieux, 'S Galu, ${ }^{2} F$ Guillemin, ' $\mathrm{JM}$ Hascoet. 'Department of Neonatology, Maternite Regionale Universitaire, Nancy Cedex; ${ }^{2}$ EA4360 APEMAC, Lorraine University, Nancy, France

Aim To determine the impact of perinatal factors on renal function in five year-old preterm-born children.

Material and Methods Prospective longitudinal study of pretermborn children from birth to five years of age, and five year-old fullterm controls. Renal function measured in the neonatal period and at five years.

Primary outcome was renal function at five years: blood pressure (BP), estimated glomerular filtration rate (eGFR), albuminuria. Multivariate analysis was performed with multiple linear regression models. 
Results 168 children included aged $5.1 \pm 0.1$ years. 133 pretermborn children, born: $29.2 \pm 1.4$ weeks gestation; 35 full-term children aged five.

Systolic BP (sBP) was $97.5 \pm 7.1 \mathrm{mmHg}$ in preterm-born children versus $92.2 \pm 8.1 \mathrm{mmHg}$ in full-term controls, $p=0.0001$. In pretermborn children, sBP increased by $(\beta \pm \sigma): 2.2 \pm 1.0 \mathrm{mmHg}$ for each $\mathrm{gram} / \mathrm{kg}$ increase in proteins/day on day 28 , and decreased by $-3.0 \pm 1.4$ in case of bronchopulmonary dysplasia, after adjustment on gender and height at five years.

eGFR was $176.3 \pm 37.1 \mathrm{~mL} / \mathrm{min} / 1.73 \mathrm{~m}^{2}$ at five in preterm-born children. It was significantly decreased when children had presented hyaline membrane disease or necrotising enterocolitis, respectively $(\beta \pm \sigma):-17.6 \pm 6.7$ and $-25.7 \pm 10.4 \mathrm{~mL} / \mathrm{min} / 1.73 \mathrm{~m}^{2}$. eGFR at five was not associated with neonatal nutrition.

$14.4 \%$ preterm-born children had an albumin ratio $>2 \mathrm{mg} / \mathrm{mmol}$ vs. $11.1 \%$ full-terms, $\mathrm{p}=0.7$.

Renal volume, absolute or relative, at five years was negatively correlated to protein intakes from day 14 onwards in the neonatal period: $R=-0.69, p=0.006$.

Conclusion Protein intakes in the neonatal period are associated to an increased BP and decreased renal volume in five year-old pretermborn children.

\section{HUMAN MILK FORTIFICATION WITH DIFFERENT AMOUNTS OF FORTIFIER AND ITS ASSOCIATION WITH GROWTH AND METABOLIC RESPONSES OF PRETERM INFANTS}

doi:10.1136/archdischild-2012-302724.1388

${ }^{1} \mathrm{HG}$ Kanmaz, ${ }^{2 B}$ Mutlu, ${ }^{2} \mathrm{FE}$ Canpolat, ${ }^{2} \mathrm{O}$ Erdeve, ${ }^{2} \mathrm{U}$ Dilmen. ${ }^{1}$ Neonatology Unit; ${ }^{2} Z e k a i$ Tahir Burak Maternity Teaching Hospital, Ankara, Turkey

Background Fortification of human milk (HM) is a common clinical practice to adapt human milk to the nutritional needs of very low birth weight infants. The optimal method for HM fortification still remains to be determined and a great variety of protocols are currently used in the neonatal intensive care units.

Objective Since it is believed that the standard fortification is insufficient to meet the needs of VLBW, we designed a randomized prospective study in which blind fortification was administered in three different amounts of fortifier and aimed to assess short term growth and metabolic responses of preterm infants.

Methods Eligible infants were randomized into three groups; standard fortification (SF), moderate fortification (MF) and aggressive fortification (AF) groups. Short term growth, feeding intolerance and urea, calcium, phosphorus, alkaline phosphatase levels were assessed.

Results Twenty six, 29 and 29 infants were eligible in SF, MF and AF group, respectively. The baseline characteristics of the groups were similar. Daily weight gain, length at discharge did not differ between groups however head circumference was significantly higher in MF and AF group when compared with SF group. Urea, calcium, phosphorus, alkaline phosphatase levels were similar between groups.

Conclusion We demonstrated that blind fortification of HM even with higher amounts than recommended by commercials was safe and did cause a marked effect on weekly increase in head circumference but not on the other anthropometric measurements and metabolic responses of preterm infants.

\section{PARENTERAL NUTRITION IN VERY LOW BIRTH WEIGHT NEWBORNS: AUDIT OF CLINICAL PRACTICE}

doi:10.1136/archdischild-2012-302724.1389

'A Madhavan, 'M Yadav. 'Manchester Medical School, University of Manchester, Manchester; '2Department of Neonatology, Royal Bolton Hospital NHS Foundation Trust, Bolton, UK
Background and Aims Parenteral nutrition (PN) is an integral part of neonatal intensive care, especially in the early nutritional support of very low birthweight (VLBW) newborns. However, it is associated with potentially serious complications such as sepsis and metabolic derangement. The aim of the study was to review PN use and complications in VLBW newborns at Royal Bolton Hospital with specific European Society of Paediatric Gastroenterology, Hepatology and Nutrition (ESPGHAN) guidelines as the standard.

Methods PN use was reviewed in all VLBW newborns who received PN for more than 1 day during January 2009 to December 2010. ESPGHAN standards audited were the time of commencement of PN and composition of the PN bag.

Results Of the 42 VLBW newborns included, the median gestational age and weight was $27^{+0}$ weeks and $923 \mathrm{~g}$ respectively. In this group, $24 \%$ of newborns met the ESPGHAN standard for amino acid commencement and $88 \%$ for lipid commencement. The glucose and phosphate content of the PN bag did not match ESPGHAN standards as the glucose content was higher and phosphate content lower than recommended. Most common PN complication was hyperglycaemia (64\%), followed by hypophosphataemia (45\%) and sepsis (38\%). Coagulase negative Staphylococci were the most common organism cultured ( $94 \%$ ).

Conclusion There was a delay in commencement of PN. To achieve full compliance with ESPGHAN guidelines, amino acids and lipids should be commenced as recommended. Modifying constituents of the PN bag may help reduce complication rates of hyperglycaemia and hypophosphataemia.

\section{BACTERIAL COLONIZATION OF PRETERM INFANTS: IMPACT OF BIOFILM FORMATION ON THE NASOGASTRIC FEEDING TUBES}

doi:10.1136/archdischild-2012-302724.1390

'M Gómez, 'L Moles, ${ }^{2} \mathrm{~A}$ Melgar, ${ }^{2} \mathrm{G}$ Bustos, ${ }^{1} \mathrm{JM}$ Rodríguez. ${ }^{1} D p t o$. Nutrición, Bromatología y Tecnología de los Alimentos, Universidad Complutense de Madrid; ${ }^{2}$ Hospital Materno Infantil 12 de Octubre de Madrid, Madrid, Spain

Background Nowadays, hospitals foment breastfeeding or human donor milk to provide the best feeding option to the preterm infant. This fact may represent a key factor in the initiation and development of the infant gut microbiota.

Aims To analyse the bacterial diversity in meconium and feces of preterm neonates and to evaluate the impact of the nasogastric enteral feeding tubes and the feeding option in its evolution.

Method 26 mother/preterm neonates ( $<32$ weeks gestation) pairs participated in the study providing a sample of colostrum/breast milk and meconium/feces. Milk samples were obtained after their pass through the nasogastric feeding tubes. Samples were plated onto different culture media. The isolates were identified by PCR sequencing. Scanning electron microscopy (SEM) was used to observe biofilm formation on the feeding tubes.

Results Approximately 4,000 isolates were identified. The dominant genera in both samples were Staphylococcus, Enterococcus, Serratia, Klebsiella and Escherichia. They were present at high concentrations independently of the feeding option. Lactobacilli and bifidobacteria were detected in a low percentage of the samples. Analysis of several parts of the nasogastric tubes by SEM revealed the presence of a dense bacterial biofilm. Biofilms were composed of the same bacterial groups that dominated in the fecal and milk/ formula samples.

Conclusions There is a direct relationship between the high bacterial concentrations found in the biological samples and the biofilm formed in the nasogastric tubes. Fecal microbiota of preterm neonates are strongly influenced by those species highly prevalent the hospitalary environment. 